\title{
Edição de crónicas e relatos sobre D. Sebastião: balanço e perspetivas
}

\author{
Edition of Chronicles and Narratives about King D. Sebastião \\ of Portugal: Current State and Perspectives
}

\author{
ELENA LOMBARDO \\ Universidade de Lisboa- \\ Centro de Linguistica \\ elenalombardo@.campus.ul.pt
}

\author{
FILIPE ALVES MOREIRA \\ Universidade do Porto- \\ SMELPS/IF/FCT \\ gomeseanes@gmail.com
}

Palavras-chave

D. Sebastião;

Batalha de

Alcácer-Quibir;

Textos historiográ-

ficos; Catálogos;

Edição de textos;

Humanidades

Digitais.
Keywords

King D. Sebastião of Portugal; Battle of Alcácer Quibir; Historiographic texts; Catalogues; Texts editions; Digital Humanities.
O estudo da historiografia portuguesa escrita nos séculos XVI e XVII tem ainda numerosas lacunas, em grande parte derivadas do facto de os estudiosos terem em conta, habitualmente, apenas textos que chegaram a ser impressos, as mais das vezes, em edições defeituosas, ignorando ou menorizando a produção que permaneceu manuscrita. Partindo desta constatação, este trabalho analisa uma área em cujo estudo se notam estas deficiências - a historiografia quinhentista e seiscentista em português sobre D. Sebastião. Constatando a inexistência de sínteses globais sobre esta matéria, define-se um corpus de textos historiográficos sobre D. Sebastião com base em critérios internos e analisa-se o estado atual do seu campo editorial, salientando as numerosas fragilidades subsistentes quanto a metodologias adotadas e resultados obtidos. Apresenta-se, também, o projeto "Sebástica manuscrita”, que visa colmatar as lacunas identificadas, e alguns dos resultados obtidos, nomeadamente a descoberta e identificação de novos relatos sobre D. Sebastião e a sistematização de dados já conhecidos.

The study of the $16^{\text {th }}$ and $17^{\text {th }}$ century Portuguese historiography is still lacunary, since specialists tend to consider only printed sources, disregarding manuscripts, and often produce poor quality editions. Bearing this in mind, in this paper, we analyze an area in which these problems are particularly evident the 16th and 17th century Portuguese historiography about King D. Sebastião. Noticing, after the completion of a thorough research, the lack of a comprehensive synthesis on this subject, we have determined to define a corpus of historiographic texts about this king, based on internal criteria, and to analyze the current state of their editions, emphasizing several gaps regarding the methodologies used and the results achieved so far. We also intend to present the project "Sebástica manuscrita", which aims at filling these gaps, and some of the results we have obtained - namely the discovery and identification of new narratives about King D. Sebastião and the systematization of already known data. 


\title{
ELENA LOMBARDO \& FILIPE ALVES MOREIRA
}

\author{
Cuando se proclamó que la Biblioteca abarcaba todos los libros, \\ la primera impresión fue de extravagante felicidad. \\ (Jorge Luis Borges, La Biblioteca de Babel, 1941)
}

O estudo da historiografia portuguesa dos séculos XVI e XVII, apesar de alguns importantes contributos, tem ainda diversas lacunas. A tendência tem sido a de reproduzir e comentar os textos fornecidos pelas edições existentes, maioritariamente antiquadas e frequentemente cheias de erros, e ignorar (ou utilizar de forma esporádica) o vasto conjunto de textos que permanecem inéditos. Este facto cria uma imagem limitada e condicionada do campo historiográfico da época e tem consequências a diversos níveis. Do ponto de vista das disciplinas históricas, obstaculiza uma visão abrangente tanto dos factos, como dos discursos que se formaram sobre eles; do ponto de vista da crítica textual, omite um conjunto de dados indispensáveis para o aperfeiçoamento do trabalho editorial; do ponto de vista linguístico, conduz à exclusão de fontes importantes para o estudo de um período que é frequentemente negligenciado pelos historiadores do português.

Neste trabalho, analisaremos o estado atual do campo editorial ${ }^{1}$ de uma tradição específica, a da historiografia sobre a figura e o reinado de D. Sebastião produzida, em português, por contemporâneos deste rei. Definiremos critérios para a constituição deste corpus e indicaremos quais os textos que foram editados, e como, e quais os que permanecem inéditos, apresentando, por fim, um projeto que visa colmatar as lacunas observadas e eventualmente aumentar o número de textos identificados.

\section{O corpus}

Comecemos pela definição do objeto, ou seja, a historiografia sobre a figura e o reinado de D. Sebastião produzida por contemporâneos do rei. Por "contemporâneos do rei", entendemos indivíduos que atingiram a idade adulta antes do termo deste reinado (1578). Uma vez que nem sempre é possível termos certezas quanto à autoria dos textos ou à biografia dos respetivos autores, adotamos o critério de considerarmos potencialmente pertinentes todos os textos e manuscritos datados, ou datáveis, até ca. 1650, bem como aqueles que tenham sido atribuídos a autores desta cronologia, mesmo que deles restem apenas testemunhos posteriores.

Mais complexa é a questão do tipo de textos considerados. Por "texto historiográfico", entendemos relatos em prosa cujo pacto de leitura/programa subjacente é o de transmitirem enunciados verídicos. São textos que se apresentavam e eram percecionados (pelo menos por boa parte dos recetores) como relatos verdadeiros de ações verdadeiras. Esta definição abrange, contudo, um conjunto muito vasto de textos, de extensão, características e propósitos variados. Parece-nos, por isso, necessário introduzir algumas clarificações e restrições.

Por razões pragmáticas, focar-nos-emos apenas em textos autónomos, excluindo relatos do reinado de D. Sebastião que fazem parte de textos mais vastos como sucede com os sumários de crónicas ${ }^{2}$. Decidimos também, por razões operacionais, dividir o corpus textual, assim delimitado, em diferentes categorias. Não havendo, à época, um sistema de géneros de tipo normativo aplicável à historiografia (como existia, por exemplo, com a poesia ou o teatro),

\footnotetext{
${ }^{1}$ Usamos esta expressão com o sentido de "conjunto de edições existentes de um grupo de textos relacionados entre si".

2 Por exemplo, o Sumário dos Reis de Portugal escrito por António Soares de Albergaria, de que subsiste pelo menos uma cópia, no COD. A.T. / L. 101 da Biblioteca Nacional de Portugal.
} 
e sendo, por isso, grande a variação de títulos, esta divisão apoia-se em critérios internos e a escolha das designações adotadas é de nossa responsabilidade.

Consideramos como critérios internos mais relevantes a existência ou não de múltiplos episódios e a forma de os relacionar, bem como a presença textual de um destinatário concreto. Com base neles, propomos a seguinte classificação tipológica:

- Crónicas: narração extensa, e por isso subdividida em unidades de sentido designadas “capítulos”, de uma série de episódios interrelacionados (e não de um evento só), dentro de um recorte temporal ou temático (por exemplo, a vida de uma personagem ou um reinado), e sem um destinatário concreto. Mais do que simplesmente contados, os eventos são enquadrados, por exemplo, através de analepses que explicam os seus antecedentes.

- Relações: relato menos extenso do que as crónicas e dirigido a um destinatário concreto (individual ou grupo de pessoas). No nosso corpus, é comum as relações serem cartas que no decurso da transmissão manuscrita perderam o carácter formulaico ${ }^{3}$. Ao contrário do que sucede com as crónicas, não são fornecidos antecedentes para os eventos narrados.

- Memórias: distinguem-se das crónicas pelo facto de o autor ser também sujeito da enunciação; distinguem-se das relações por não terem um destinatário concreto. Podem ser mais ou menos extensas e podem ter carácter autobiográfico.

- Anedotas: narrações breves, com traços cómicos ou exemplares, que se ocupam exclusivamente de uma ação.

Excluiremos da nossa análise a última destas quatro categorias. As anedotas existem, com efeito, em enorme quantidade e, pela sua brevidade, aparecem nos mais diversos meios (escritas ou copiadas em miscelâneas, em impressos, nas margens ou nas folhas finais de crónicas etc.). Não é possível pretender-se, alguma vez, abarcar todas elas. Algumas já foram sendo, de resto, editadas, ao sabor de diferentes interesses e gostos ${ }^{4}$.

\section{Os relatos sobre D. Sebastião: estado da questão}

\subsection{Visões de conjunto}

O estudo dos textos historiográficos dos séculos XVI e XVII dedicados ao reinado de D. Sebastião tem sido feito de forma parcelar, intermitente e fragmentária. Mais do que objeto específico de análise sob o ponto de vista literário, filológico ou linguístico, estes textos têm sido encarados, quase exclusivamente, como materiais para o estudo de outras temáticas - a partir do já clássico D. Sebastião 1554-1578 de Queirós Veloso (1935). Consequentemente,

\footnotetext{
3 Uma notável exceção é a Carta a um abade da Beira, de que existem muitas cópias e que foi já editada (por exemplo, em Ribeiro, 1960, que dá a conhecer duas versões distintas deste texto). Facilmente classificável de "Relação" segundo os critérios aqui definidos, este texto mantém, contudo, em muitos testemunhos, os aspectos formulaicos típicos das cartas. A figura do abade destinatário é, por outro lado, certamente uma ficção. Estas características tornam este texto um caso à parte dentro do corpus aqui delineado.
}

${ }^{4}$ Veja-se, por exemplo, Lund (1980). 


\section{ELENA LOMBARDO \& FILIPE ALVES MOREIRA}

faltam ainda instrumentos básicos como um elenco de textos e respetivas edições e/ou manuscritos.

A mais completa bibliografia sobre D. Sebastião é a Sebástica: bibliografia geral sobre D. Sebastião (Oliveira, 2002) e constitui sem dúvida uma ferramenta fundamental para quem pretenda debruçar-se sobre este assunto. A Sebástica contém cerca de 3700 entradas, organizadas em oito secções (História, Sebastianismo e Quinto Império, Poesia, Artes do Espetáculo, Ficção, Divulgação, Iconografia e Bibliografia), em que se visa abordar a figura do rei, respetivamente, "enquanto pessoa, mito, personagem ou fonte inspiradora" (Oliveira, 2002: $\mathrm{XXI}$.

Oliveira ambiciona oferecer ao público uma bibliografia integral, que abarque todos os aspectos relacionados com D. Sebastião. Um projeto desta envergadura, por completo que pretenda ser, deverá, necessariamente, impor-se algum limite metodológico, que, neste caso, é representado pelo modo de transmissão das obras incluídas: o autor indica-o na página XIX, onde diz que a Sebástica "desejaria ser a reunião exaustiva dos títulos de obras impressas referentes a D. Sebastião" (negrito nosso). Esta escolha, mencionada de passagem, parece explicar algumas imprecisões contidas na Introdução, nomeadamente a ideia de que não existem relações portuguesas sobre a batalha de Alcácer-Quibir coevas aos acontecimentos (Oliveira, 2002: XXV) 5 .

Esta ideia é, na verdade, recorrente. Para além do catálogo de Oliveira, outro exemplo é um artigo de Jacqueline Hermann de 2006, especificamente sobre a batalha de Alcácer-Quibir ${ }^{6}$. A autora delimita o objeto de estudo em duas ocasiões: no resumo, fala em "crónicas" (Hermann, 2006: 11) e, na página 20, especifica que não vai considerar as "primeiras notícias do desastre em Portugal e Espanha" e sim as "versões da batalha que surgiram pouco tempo depois do conhecimento da derrota". Deve, portanto, entender-se que é com referência a este tipo de documentos que afirma: "os primeiros relatos conhecidos são de estrangeiros" (Hermann, 2006: 12). Todavia, na cronologia dos textos que é apresentada na segunda parte do artigo, Hermann inclui textos estrangeiros impressos a partir de 1578, a Crónica del-Rey D. Sebastião de Miguel Pereira ${ }^{7}$, a Miscelânea do sítio de Nossa Senhora da Luz do Pedrogão Grande de Leitão de Andrade ${ }^{8}$, a Crónica de D. Sebastião atribuída a Frei Bernardo da Cruz ${ }^{9}$ e outros textos publicados apenas nos séculos XIX e XX. Note-se, antes de tudo, que os textos indicados são tanto manuscritos, como impressos e que, mais uma vez, a menção de edições modernas de manuscritos antigos deveria ter alertado a autora para a possível existência de outros hoje

\footnotetext{
${ }^{5}$ Oliveira refere um estudo de Henry de Castries (1905) e escreve: "relativamente à batalha, Castries reconhece não haver relações portuguesas coevas" (Oliveira, 2002: XXV, negrito nosso). Note-se que, na verdade, Castries comentara: "um tal evento [a batalha] deveria ter deixado, ao que parece, a sua marca em inúmeras relações, tanto manuscritas, como impressas. Mas não foi assim: os relatos coevos são pouco numerosos, tanto em Espanha como em Portugal" (Castries, 1905: 395, negrito nosso. No original: "un pareil événement aurait dû, à ce qu'il semble, laisser sa trace dans de nombreuses relations, soit manuscrites, soit imprimées. II n'en est rien: les récits contemporains sont peu nombreux, en Espagne comme en Portugal").

6 "El-Ksar El-Kebir: Narrativas e história sebástica na Batalha dos três reis - Marrocos, 1578". Veja-se, também, Hermann (1998).

${ }^{7}$ A Crónica de Miguel Pereira foi publicada em 2018, numa edição coordenada por António Brehm, que mais adiante voltaremos a comentar.

8 Impressa em Lisboa, em 1629, por Mateus Pinheiro.

9 Publicada em 1837, por Alexandre Herculano e António da Costa Paiva.
} 
desconhecidos. Além disso, um dos textos citados - a Crónica do Xarife Mulei Mabamet e del-Rey D. Sebastião ${ }^{10}$ - foi escrito com toda probabilidade ainda em 1578, o que pode apontar para a existência, pelo menos residual, de relatos portugueses escritos pouco depois da batalha. Finalmente, causa perplexidade a inclusão, entre as "crônicas anônimas", da Memória acerca da batalha de Alcácer-Quibir, que é, na realidade, um estudo do século XIX"11.

Três outros autores debruçaram-se sobre o assunto de forma, a nosso ver, mais rigorosa. O primeiro é Queirós Veloso. No seu já clássico Estudos históricos do século XVI (1950), discute a autoria da Crónica de D. Sebastião atribuída a Frei Bernardo da Cruz, refutando esta atribuição e sustentando a tese da autoria de António de Vaena. Apesar de o estudo ser já datado em muitos aspectos, trata-se de uma fonte preciosa para o estudo das tradições manuscritas de muitos dos relatos sebásticos.

O segundo é José Manuel Garcia, no artigo “A Batalha de Alcácer Quibir e a cronística portuguesa" (2011)12. Mesmo partindo da constatação da "relativa escassez de registos de cunho historiográfico de origem portuguesa que narraram o acontecido nessa batalha" e do facto de "se ter verificado a não publicação imediata em Portugal de obras sobre o assunto e o rei em questão, as quais só surgem bastantes anos depois” (2011: 377), Garcia relativiza tal escassez e dedica-se ao estudo dos manuscritos inéditos existentes em bibliotecas portuguesas, trazendo à luz dados novos e discutindo as tradições de numerosos testemunhos. Para além disto, publica um excerto da Crónica de Miguel Pereira em transcrição modernizada.

Ao contrário do que acontece com os autores previamente referidos, Garcia distingue cronística oficial (obras patrocinadas pela própria Coroa) de outros textos, mostrando que, apenas em relação à primeira destas categorias, se pode afirmar a inexistência de obras coevas.

Isto não implica, todavia, que tentativas nesta direção não tenham sido feitas já a partir de Frei Bernardo de Brito (cronista-mor entre 1614 e 1617). De acordo com Garcia, a existência dos códices 49-XI-75 e 49-XI-77 da Biblioteca da Ajuda (BA), que referem o nome de Bernardo de Brito, confirmaria que este autor chegou a recolher material para uma crónica de D. Sebastião ${ }^{13}$.

O mesmo teria chegado a fazer João Baptista Lavanha (cronista-mor entre 1618 e 1624), como o demonstraria a existência do COD. 887 da Biblioteca Nacional de Portugal (BNP), intitulado Relações das cousas principaes q sucederão em Portugal em tempo del Rey D. Sebastião / tiradas de originaes do Reyno per João Bap.ta Lavanha, Coronista mor do R.no de Portugal para fazer esta Coronica. Para além disso, Garcia também sugere que o ALC. 308 da BNP e o Portugais 8 da Biblioteca

\footnotetext{
${ }^{10}$ Os três manuscritos deste texto (MSS. 2422 da Biblioteca Nacional de Espanha, COD. 13282 da Biblioteca Nacional de Portugal e CIII/1-14 da Biblioteca Pública de Évora) foram editados, respetivamente, em edição modernizada por Sales Loureiro (1987), em edição diplomática e semidiplomática por Lombardo (2015) e em edição diplomática por Lombardo (inédito).

11 "Sales Loureiro publicou a Jornada del-Rei dom Sebastião às partes da África, a Crónica de dom Henrique, a Crónica do Xarife Mulei Mahamet e D'El-Rei D. Sebastião e o relato de Eduardo Alvarez, Memória acerca da batalha de Alcácer Quibir, este publicado em 1892" (Hermann, 2006: 24). Notese, também, que esta frase parece atribuir a Sales Loureiro (1919-2000) a edição deste último texto.

12 Já anteriormente, este autor havia prestado atenção a uma parte da historiografia sobre D. Sebastião. Veja-se Garcia (2006).

${ }^{13}$ As alusões ao trabalho de Frei Bernardo de Brito são muitas. Veja-se, por exemplo, Frei Fortunato de São Boaventura (1827: 135-136).
} 


\section{ELENA LOMBARDO \& FILIPE ALVES MOREIRA}

Nacional de França possam estar relacionados com o COD. 887 e, consequentemente, com a figura de Lavanha ${ }^{14}$.

Para Garcia, a inscrição, no COD. 887, da epígrafe "em casa de Francisco de Lucena, secretário de Estado, recebi este livro em 28 de Junho de 1626” (apud Garcia, 2011: 378), revelaria que D. Manuel de Meneses (cronista-mor entre 1625 e 1628) recebeu, por sua vez, o códice e a incumbência de escrever uma crónica de D. Sebastião. Supõe-se que tenha chegado a cumprir o pedido ${ }^{15}$, mas não temos hoje testemunhos manuscritos da obra e ainda estão por definir as relações entre este autor e a crónica que foi publicada em seu nome em $1730^{16}$. Garcia sugere que o Principio do governo de D. Sebastião (refere-se ele ao exemplar da Torre do Tombo, Casa Fronteira, M-VII-17) poderia estar relacionado com esta crónica perdida.

$\mathrm{Na}$ segunda parte do artigo, a escrita sobre D. Sebastião é abordada a partir dos textos de cronistas não oficiais, tanto impressos, como manuscritos.

Garcia cita a Jornada de África de Jerónimo de Mendonça ${ }^{17}$, a Crónica do Xarife Mulei Mahamet, a Miscelânea de Miguel Leitão de Andrade, a Jornada escrita por um Homem africano (anónima) ${ }^{18}$, a Jornada del Rey D. Sebastião atribuída a Fernando de Góis Loureiro ${ }^{19}$, a Crónica atribuída a Frei Bernardo da Cruz, a Relação da vida D’ElRey D. Sebastião do Padre Amador Rebelo $^{20}$ e a Crónica de Miguel Pereira. Para a Jornada atribuída a Góis Loureiro, propõe a autoria alternativa de D. Gil Eanes da Costa, com base em Diogo Barbosa Machado (1747: 382), mesmo que o seu argumento não encerre definitivamente a questão, como o próprio reconhece ${ }^{21}$.

\footnotetext{
${ }^{14}$ Frei São Boaventura (1827) já tinha ligado o BNP, ALC. 308 (olim Alc. 443) a João Batista Lavanha. Sobre a carta de Rui Barreto de Meneses contida no ALC. 308 (1618), é curioso notar que Francisco de Sales Mascarenhas Loureiro afirmou, na Introdução à sua edição da Jornada del-rei dom Sebastião à África (1978), que Rui Barreto de Meneses estaria a dirigir-se a D. Manuel de Meneses (cronista entre 1625 e 1628). Garcia conhecia certamente este texto de Sales Loureiro, pois cita-o na página 379, mas não se the refere na passagem que acabamos de comentar. Quanto ao BNF, Portugais 8, trata-se do citado por Castries (1905).

15 D. Francisco Manuel de Melo (1608-1666) afirma ter visto o trabalho de D. Manuel de Meneses in fieri (Epanaphoras de varia historia portugueza, II: 268). Para além disso, segundo Barbosa Machado (Bibliotheca Lusitana, 1752: 312), em 1752, na Biblioteca da Alcobaça, ainda existiria uma cópia desta crónica, hoje desconhecida, que foi utilizada por Frei Manuel dos Santos (cronista entre 1729 e 1740), para a redação da sua História sebástica (1735).
}

${ }^{16}$ Chronica do muito alto, e muito esclarecido principe D. Sebastiaõ decimosexto rey de Portugal composta por D. Manuel de Meneses [...] Primeira parte. Lisboa: Oficina Ferreyriana, 1730. Vários autores propõem que esta crónica tenha sido escrita ou, pelo menos, publicada por José Pereira Baião (veja, por exemplo, Barbosa Machado, 1747, 1752; Inocêncio da Silva, 1860: 97; 1862: 60; Herculano; Paiva, 1837: XI-XII).

17 Publicada, em 1607, em Lisboa, na Oficina de Pedro Craesbeek.

18 Publicada, em edição modernizada, em 2004, por Conceição Pedro e Calapez.

${ }^{19}$ Publicada, em 1978, por Francisco de Sales Mascarenhas Loureiro.

20 Publicada, em 1977, por Francisco de Sales Mascarenhas Loureiro.

${ }^{21}$ É interessante notar que, dado que Sales Loureiro nunca indicou a cota do manuscrito de Viseu, que edita, e que até hoje não foi possível encontrar este exemplar, todos os autores que queiram fazer referência à Jornada e que desconheçam os demais manuscritos do texto têm, necessariamente, de tomar como ponto de partida a transcrição de Sales Loureiro. É isto que acontece também no caso de Garcia: o trecho que lhe serve de argumento para a autoria alternativa é por ele transcrito com base na edição de 1978, modernizada. 
À Crónica atribuída a Frei Bernardo da Cruz é dedicado muito espaço, em que se apresenta, comentando-o, o longo debate acerca da sua autoria. Para defender a atribuição a Frei Bernardo da Cruz, Garcia aceita a argumentação suportada por Augusto Ferreira do Amaral (1982) e adiciona que o primeiro registo da autoria de Bernardo da Cruz "foi expresso por Manuel de Sampaio da Silva, numa cópia que fez desta crónica" (Garcia, 2011: 382).22 Sugere que as intervenções feitas no final da crónica poderiam ser de autoria de António de Castilho, que foi guarda-mor da Torre do Tombo (TT) desde 1582. A seguir, refuta todas as demais autorias atribuídas à Crónica ao longo do tempo e apresenta a hipótese da existência de três famílias de manuscritos da Crónica: uma em que se reporta o nome de Frei Bernardo da Cruz, outra relacionada com a Crónica do Cerco de Mazagão de Vaena e uma terceira sem qualquer referência autoral, à qual foram posteriormente associados os nomes de outros autores.

Garcia cita ainda a Relação da vida D'E/Rey D. Sebastião por Amador Rebelo e esclarece, ampliando as afirmações de Sales Loureiro (1977), que o texto teve uma primeira versão, que foi acabada em 6 de novembro de 1613 e revista em 3 de agosto de 1616.

Por fim, introduz a Crónica de Miguel Pereira, que diz ser a única ainda inédita daquelas por ele citadas. Refere a existência de dois testemunhos (BNP, COD. 477 e BA, 49-XII-1) e publica um excerto em transcrição modernizada dos fólios 60 a 63 do testemunho da BNP.

Merece também referência uma comunicação de Rui Loureiro de 2018. Em "Práticas de escrita entre os cativos portugueses em Marrocos: alguns comentários à Crónica de Almançor", Loureiro indicia a existência de relatos portugueses coevos, admitindo que

os cativos portugueses trocavam frequentemente cartas com correspondentes em Portugal; preparavam relatórios sobre diversos aspectos do mundo marroquino; redigiam peças de teatro, poemas e tratados místicos; e tomavam apontamentos sobre as mais variadas questões, nomeadamente sobre a história de Marrocos. (Loureiro, 2018: 28-29)

A partir de dados da Crónica de Almançor²3, Loureiro analisa textos como o Cancioneiro de D. Maria Henriques ${ }^{24}$ e a Crónica do Xarife Mulei Mabamet, chegando a apoiar a hipótese de Lombardo (2015), da possível consulta de fontes escritas por parte dos cativos, e realçando a importância deste conjunto esquecido de obras para o estudo da história da batalha e dos seus desfechos.

\subsection{O campo editorial}

Exceto o estudo de Queirós Veloso e o artigo de Garcia, não temos notícia de tentativas de sistematização dos dados existentes sobre a tradição manuscrita do corpus de relatos sobre D. Sebastião. Este acervo, disperso por bibliotecas de diversos países, apenas indireta ou fragmentariamente é referenciado pelos estudiosos e o nosso conhecimento limita-se às informações das poucas edições existentes, sendo que inúmeros textos permanecem inéditos, incorretamente catalogados ou até mesmo desconhecidos. Quase todos os que chegaram a ser editados foram-no sem que se houvesse recorrido a processos modernos de crítica textual: para além da multiplicação de leituras erróneas e da aplicação de critérios pouco respeitosos do

\footnotetext{
22 Provável alusão ao manuscrito da Academia das Ciências de Lisboa, n. 688, tal como se depreende de Queirós Veloso (1935: 148).

23 Publicada, em 1997, por António Dias Farinha com tradução de Léon Bourdon.

24 Publicado, em 1956, por Domingos Maurício Gomes dos Santos.
} 


\section{ELENA LOMBARDO \& FILIPE ALVES MOREIRA}

testemunho editado, as edições raramente consideram a totalidade da tradição manuscrita do texto que estão a editar e casos há em que nem sequer os critérios ou a cota dos manuscritos objeto de edição são apresentados.

Francisco de Sales Mascarenhas Loureiro é disto um bom exemplo. Sales Loureiro foi responsável, entre os anos 70 e 90 do século XX, pela publicação de uma grande parte dos relatos sebásticos coevos hoje conhecidos (Relação da vida d'Elrey D. Sebastião, 1977; Jornada delrei dom Sebastião à Africa, 1978 e Crónica do Xarife Mulei Mahamet e del-Rey D. Sebastião, 1987, para além da Relação da jornada de El-Rey D. Sebastião quando partiu da cidade de Évora, 1984). Todavia, a falta de conhecimentos linguísticos e dos procedimentos da crítica textual necessários à compreensão dos manuscritos editados, o seu viés ideológico assumido (a reabilitação da figura do rei D. Sebastião) e a falta de sistematicidade na apresentação dos dados limitam a utilidade do seu trabalho.

A edição da Crónica do Xarife Mulei Mabamet e del-Rey D. Sebastião já foi comentada em Lombardo $(2015$; 2016). Outro caso significativo é a edição da Jornada del-rei dom Sebastião à África que, como já notámos acima, carece da indicação da cota do manuscrito de base ${ }^{25}$. $\mathrm{O}$ historiador alude aos critérios seguidos para a transcrição, mas a falta de referências à cota impede de verificar a sua correta aplicação. As Breves considerações de natureza diplomática que concluem o Prefácio não são suficientes, pois denotam um estranhamento em relação ao objeto de estudo tanto nos seus aspectos linguísticos, como codicológicos, alimentando o receio de que se trate de uma edição pouco válida no que concerne ao tratamento do original. $\mathrm{Na}$ opinião do historiador, por exemplo, as "formas divergentes de ortografia, em relação à mesma palavra, estranhamente surgem a escassas páginas umas das outras, quando não na mesma página e até nesta, a breves linhas de distância” (Sales Loureiro, 1978: LIX, negrito nosso). Um "apóstrofo", no seu dizer, seria utilizado "para indicar a supressão de uma letra, geralmente nasal, em meio da palavra. Tal se dá, por exemplo, na palavra bo'rra, a cuja forma preferimos hõrra" (LX). As anotações paleográficas limitam-se a: "estranha-se que no original o autor apresente os títulos dos capítulos em forma ortográfica e de redacção bastante mais descuidadas do que as que encontramos no seu desenvolvimento. Por vezes sugere outra ortografia" (LXI). Veja-se, também, que Sales Loureiro confunde frequentemente os conceitos de autor e copista.

Mais modernamente, destaca-se o caso da edição da Crónica de El Rey D. Sebastião de (suposta) autoria de Miguel Pereira, coordenada por António Brehm (2018). A edição contém uma Introducão bem documentada, mas discutível em alguns pontos, nomeadamente na cronologia apresentada para os relatos sobre D. Sebastião. Quanto à edição propriamente dita, o aspecto mais problemático é que mostra não conhecer outros manuscritos para além do da BNP, ignorando o da BA, já noticiado por Garcia (2011), e um outro testemunho pertencente aos fundos da TT, que mais adiante voltaremos a referir.

Para completar o quadro, muitas destas edições são antigas. $O$ caso exemplar é o da Crónica atribuída a Frei Bernardo da Cruz: muito se tem escrito sobre o assunto, sobretudo no que concerne ao problema da autoria, mas ninguém ainda empreendeu uma nova tentativa de estabelecimento do texto que tivesse em consideração a totalidade dos testemunhos à disposição. Até hoje, existem apenas duas edições: a de 1837, por Herculano e Paiva, e a de 1925, por António Ferreira da Serpa. Serpa publicou o manuscrito ANTT, Livraria n. 982,

\footnotetext{
25 Ressalvamos, porém, a possibilidade de, à data desta edição, o manuscrito não ter uma cota. Como já dissemos acima, até hoje, não nos foi possível localizá-lo na Biblioteca de Viseu.
} 
acreditando tratar-se de um texto inédito do Padre Amador Rebelo, tal como reportado pelo título do exemplar, e não de outro testemunho da Crónica de Bernardo da Cruz. Para além disso, de acordo com Queirós Veloso (1935: 155), este testemunho contém muitos erros. Por estas e outras razões, a edição mais utilizada é a de Herculano e Paiva, baseada no manuscrito 356 da Biblioteca Pública Municipal do Porto (BPMP). Esta edição está disponível online, mas está datada tanto em relação aos métodos utilizados, como porque muitos dos manuscritos hoje catalogados não eram então conhecidos.

\section{3. "Sebástica manuscrita": projeto e novos dados}

Face a esta situação, ao longo de 2018, dedicámo-nos a uma primeira catalogação de textos historiográficos manuscritos existentes nas principais bibliotecas do País, pondo as bases para um projeto, a longo prazo, no âmbito do Centro de Linguística da Universidade de Lisboa. O projeto "Sebástica manuscrita: catálogo e edições digitais de textos historiográficos portugueses dos séculos XVI e XVII" tem como objetivo final a construção de um website em que estejam reunidos e sistematizados os dados relativos às tradições manuscritas dos textos historiográficos sobre D. Sebastião redigidos em português por contemporâneos do rei, juntamente com edições filológicas digitais linguisticamente anotadas destes textos. Consideraremos os textos manuscritos que se enquadrem na tipologia mencionada no início deste artigo, quer se encontrem em bibliotecas nacionais ou internacionais.

Neste momento, disponibilizamos ao público a catalogação preliminar dos testemunhos identificados em acervos portugueses: em Lisboa, na Biblioteca Nacional de Portugal, na Biblioteca da Ajuda, na Academia das Ciências de Lisboa e no Arquivo Nacional da Torre do Tombo; no Porto, na Biblioteca Pública Municipal; em Évora, na Biblioteca Pública; em Coimbra, na Biblioteca Geral da Universidade; em Viseu, na Biblioteca Municipal.

O catálogo encontra-se na página http://www.clul.ulisboa.pt/pt/24-recursos/923sebastica-manuscrita-catalogo-e-edicoes-digitais-dos-textos-historiograficos-portugueses-dossecs-xvi-e-xvii. Trata-se de uma versão em constante atualização, padronização e correção, de acordo com o andamento das nossas investigações. Atualmente (abril 2019), consta de 13 núcleos textuais e contém 91 manuscritos e 22 referências bibliográficas.

Para ordenar os testemunhos de cada núcleo textual, decidimos adotar um critério pragmático - o do local de guarda dos manuscritos. Assim, enumeram-se os manuscritos agrupados por biblioteca e, quando possível, no interior destes grupos, por ordem cronológica de cópia.

Cada núcleo textual está identificado por: a. um título convencional que pode ser o atribuído pela crítica ou o contido no(s) manuscrito(s) existente(s); b. o nome do autor, quando conhecido; c. a data de redação, sempre que possível. Procurámos não atribuir novos nomes quando não necessário, de maneira a evitar a proliferação de denominações e a multiplicação de equívocos.

Cada testemunho está identificado primeiramente por uma sigla constituída pelo local de guarda e pela respectiva cota de identificação. Indicamos o título do texto e, quando possível, a data de cópia. $\mathrm{Na}$ falta de datas precisas, reportamos o século.

A secção seguinte contém os dados materiais dos manuscritos: dimensões, número de fólios, a descrição de eventuais folhas de rosto e, quando possível, um esquema da organização do conteúdo. Finalmente, mencionamos a eventual existência de digitalizações ou microfilmes do manuscrito, juntamente com a respetiva cota. 


\section{ELENA LOMBARDO \& FILIPE ALVES MOREIRA}

As fichas indicam também a existência de bibliografia e/ou de eventuais edições de pelo menos um dos manuscritos citados.

Evidenciamos com um ponto de interrogação todos os campos que não verificámos, sobretudo porque ainda não foi possível consultar os manuscritos presencialmente: tal acontece, sistematicamente, para os manuscritos da Biblioteca Municipal de Évora e para os da Biblioteca Universitária de Coimbra. Os dados inseridos entre [] são produtos de conjeturas.

As principais vantagens e mais valias deste catálogo são a sistematização de dados até agora dispersos e a identificação de novos textos e/ou testemunhos. Assim, até ao momento:

1. Identificámos alguns manuscritos (catalogados ou não) de textos que supomos até hoje desconhecidos:

- [BNP, COD. 498] Anónimo - Relação da infeliz jornada d'El Rei D. Sebastião;

- [BA, 51-IX-22] Anónimo - Jornada de África del Rey D. Sebastião;

- [ANTT, Manuscritos da Livraria, n. ${ }^{0}$ 1113/32] Manuel Teixeira - Sumario breve das coisas que vio e alcansou saber manoel teix.ra da vida del Rey d. Sebastião.

2. Verificámos, aumentámos e sistematizámos os dados relativos a textos já editados:

Bernardo da Cruz - Crónica de D. Sebastião:

- os manuscritos BNP, PBA, 186 BNP, COD. 6831; BNP, ATL 70; BNP, COD. 13282; BNP, COD. 13312; BGUC, Ms. 557 estavam catalogados, mas até agora não encontramos referências a eles nos estudos existentes sobre esta crónica;

o BA, 49-XII-1 era certamente conhecido por Garcia (2011) e por Sales Loureiro (1977), mas estes autores citam-no a respeito das tradições manuscritas da Crónica de Miguel Pereira e da Relação do P. Amador Rebelo, respetivamente.

Amador Rebelo - Relação da vida d'elrey D. Sebastião: os testemunhos BNP, COD. 6831 e ACL, MS. 171 (Série vermelha) estavam catalogados, mas até agora não encontramos referências a eles nos estudos existentes sobre esta crónica.

Fernando de Góis Loureiro - Jornada del Rey D. Sebastião: o testemunho BNP, mss. 206, num. 206 está catalogado, mas até agora não encontramos referências a eles nos estudos existentes sobre esta crónica.

Miguel Pereira - Crónica de El Rey Dom Sebastiam: a edição coordenada por Brehm (2018) só cita o BNP, COD. 477; o BA, 49-XII-1 foi citado por Garcia (2011); o ANTT, Condes da Póvoa, liv. 12, apesar de catalogado, não parece ter sido referido em estudos.

Anónimo - Relacão do princípio do governo de D. Sebastião: o ANTT, Casa Fronteira e Alorna, liv. 17 (ex Biblioteca da Fronteira, M-VII-17) foi editado por Ribeiro (1960); o BNP, Alc. 308 (olim Alc. 443) e o BA, 49-XII-1 são citados por vários autores, mas sempre em relação à tradição manuscrita de outros textos. Como já dissemos acima, Garcia (2011) levanta a hipótese de que possa tratar-se de um texto ligado à Crónica desaparecida de Manuel de Meneses. 
Anónimo - Relacões ao D. Paulo Afonso: Castries (1905) edita o BNF, Portugais 8; Dornelas (1919) edita o BNP, ALC. 308; o BNP, COD. 8570//40 está catalogado, mas até agora não encontrámos referências em estudos.

3. Sistematizámos os dados relativos à anónima Relação muito certa do apparato da armada para Africa o anno de 78 - um texto conhecido, mas que acreditamos não ter sido, ainda, editado.

4. No caso dos seguintes textos, limitámo-nos a inserir os dados já conhecidos, não tendo que acrescentar nada ao que já tinha sido publicado:

- Anónimo - Jornada de Africa del Rey D. Sebastião escrita por um Homem Africano;

- Pedro Rodrigues Soares - Memorial;

- Anónimo - Crónica do Xarife Mulei Mabamet e del-Rey D. Sebastião/Sumario de todas as cousas succedidas em Berberia: o testemunho da BPE, CIII/1-14, já catalogado, tinha sido identificado por Filipe Alves Moreira, anteriormente ao começo desta investigação.

De momento, daremos notícia sumária dos textos desconhecidos, adotando a forma do catálogo.

[BNP, COD. 498] Anónimo - Relação da infeliz jornada d'El Rei D. Sebastião

Cópia do século XVII.

Conteúdo: trata-se de uma narrativa de autor desconhecido, que abrange factos acontecidos entre o período que antecede a jornada de D. Sebastião a África e a sua morte na Batalha de Alcácer Quibir, em 1578. Sem título: o que adotamos é convencional. Não tem capítulos. Incipit: "Lição he dos sanctos e doutores graves ensinar nos...”. Explicit: “... que a todos deu nesta vida perpetua fama e na outra gloria ininfinita lustra lustrorum amen".

Descrição: 35 fls. +6 de guarda (3+3). Ex libris no $3^{\circ}$ fl. de guarda: "He de Francisco x.er de Payva / e Cardozo". In-4º 16 linhas. Papel; encadernação em pergaminho. Cópia incompleta em letra uniforme.

Referenciado em: MONIZ, José António (1896) Inventario. Secção XIII - Manuscriptos. Lisboa: BN. ${ }^{26}$

[BA, 51-IX-22] Anónimo - Jornada de África del Rey D. Sebastião;

Cópia do século XVII.

Conteúdo: 55 capítulos. Incipit: "Era el Rey Dom Sebastiaõ de tanto animo e esforco e taõ valerozo e zeloso" Capítulo 1. O Aprisibimto quesefez pa esta Jornada. Capítulo 55. falisimto do P.e frej Jnacio de Jihus em marocos da ordem dasantissima trindade

Descrição: ca. de 30 linhas por página; reclames em todos os fls. Papel. Letra humanista cursiva. Encadernação em carneiro, simples, sem nervos e sem título na lombada.

[ANTT, Manuscritos da Livraria, n. ${ }^{\circ}$ 1113/32] Manuel Teixeira - Sumario breve das coisas que vio e alcansou saber manoel teix.ra da vida del Rey d. Sebastião.

Finais do século XVI. 26 Disponível em http://purl.pt/183/4/b-1272-a_PDF/b-1272-a_PDF_24-C-R0150/b-1272-
a_0000_capa-capa_t24-C-R0150.pdf. 


\section{ELENA LOMBARDO \& FILIPE ALVES MOREIRA}

Conteúdo: Incipit: "Na era de 1554 Reynando o mui catolico e serenissimo Rey don Joao o $3^{\circ}$ deste nome faleçeo Eo princepe ..." Explicit: "quando em arzila nos cõtarão as tristes nouas e dai a dous dias partimos p.a o Reino".

Ao longo do texto há: Fala do cardeal; fala del Rey; Carta de Pero Alcáçova Carneiro. Descrição do que fez a frota del Rey em Larache. "e no derradeiro que era bespora de nossa sñora das neues vimos a fumaça e ouuimos o som dos tiros p.a a parte de alcaçere onde elRey estava pelejando cõ os mouros...".

Descrição: 5 fls. Letra gótica cursiva.

Disponibilidade: disponível em https:/ / digitarq.arquivos.pt/viewer?id=7499814.

\section{Perspetivas futuras}

Reunir o que está disperso e/ou insatisfatoriamente referenciado é um sonho recorrente na história da bibliografia e as consequências do seu utópico conseguimento estão expressas na epígrafe da Biblioteca de Babel de Jorge Luís Borges que encabeça este artigo. Todavia, no caso dos textos sobre D. Sebastião dos séculos XVI e XVII, o projeto persegue também outros objetivos. Uma vez catalogados, os manuscritos serão objeto de edições semidiplomáticas em formato digital, com a dupla finalidade de preencher as lacunas nos campos bibliográficos (Castro; Ramos, 1986) das obras e de construir um corpus para estudos de história do português clássico.

Este projeto a longo prazo passará por algumas fases. Em primeiro lugar, pretendemos completar o catálogo dos exemplares guardados nos maiores arquivos e bibliotecas nacionais. Destes, editaremos, num primeiro momento, os textos inéditos e de testemunho único, passando depois aos que possuem múltiplos testemunhos. O conjunto formado pelo catálogo e pelas edições digitais dos manuscritos com respectiva anotação morfossintática será estruturado como um corpus de informações ligadas, visualizável em formato de grafo, e formará uma biblioteca digital, de acesso livre e aberto, hospedada na plataforma TEITOK do Centro de Linguística da Universidade de Lisboa. Desta maneira, pretendemos, finalmente, disponibilizar ao público um conjunto de dados fundamentais acerca da transmissão manuscrita dos relatos sobre D. Sebastião.

\section{BIBLIOGRAFIA:}

AMARAL, Augusto Ferreira do (1982). António de Vaena e a Crónica D'El-Rei D. Sebastião. Lisboa: Editora Gráfica Portuguesa.

BARBOSA MACHADO, Diogo (1747). Biblioteca Lusitana. Tomo II. Lisboa: Oficina de Ignácio Rodrigues.

BARBOSA MACHADO, Diogo (1752). Biblioteca Lusitana. Tomo III. Lisboa: Oficina de Ignácio Rodrigues.

CASCÃO, João (1984). Relação da jornada de El-Rei D. Sebastião quando partiu da cidade de Évora. In Francisco de Sales Mascarenhas LOUREIRO, Uma jornada ao Alentejo e ao Algarve (pp. 77-136). Lisboa: Livros Horizonte.

CASTRIES, Henry de (1905). Les Relations de la Bataille de El-Ksar El-Kebir. Note critique. Les Sources Inédites de L'Histoire du Maroc de 1530 à 1845 - Archives et bibliothèques de France, tome I, 395-405. Paris: Ernest Leroux Éditeur.

CASTRO, Ivo \& RAMOS, Maria Ana (1986). Estratégia e táctica de transcrição. In Eugenio ASENSIO et al. (eds.), Critique textuelle portugaise (Paris, 1981). Actes du colloque (pp. 99122). Paris: Fondation Calouste Gulbenkian. 
Chronica de El Rey D. Sebastião. Edição por António BREHM et al. (2018). Funchal: Imprensa Académica.

Chronica de-el rei D. Sebastião por Fr. Bernardo da Cru₹. Edição por Alexandre HERCULANO \& António da Costa PAIVA (1837). Lisboa: Galhardo e Irmãos.

Cronica de El-Rei Dom Sebastião: único dêste nóme e dos Reis de Portugal o 16º compósta pelo Padre Amadôr Rebêlo, companheiro do Padre Luís Gonçalves da Câmara, Mestre do dito Rei Dom Sebastião. Edição de António Ferreira da SERPA (1925). Porto: Livraria Civilização.

Chronica do muito alto, e muito esclarecido principe D. Sebastiaõ decimosexto rey de Portugal composta por D. Manuel de MENESES [...] Primeira parte (1730). Lisboa: Oficina Ferreyriana.

COSTA, D. Francisco da (1956). Cancioneiro de Dona Maria Henriques. Introdução e notas de Domingos Maurício GOMES DOS SANTOS. Lisboa: Agência Geral do Ultramar.

Crónica de Almançor, Sultão de Marrocos (1578-1603), de António de Saldanha/Chronique D'AlMansour, Sultan du Maroc (1578-1603), de António de Saldanha. Estudo crítico, introd. e notas por António DIAS FARINHA; trad. Léon BOURDON (1997). Lisboa: Instituto de Investigação Científica Tropical.

Crónica do Xarife Mulei Mahamet e del-Rey D. Sebastião 1573-1578. Leitura, introdução e notas por Francisco de Sales Mascarenhas LOUREIRO (1987). Lisboa: Europress.

DORNELAS, Afonso de (1919). Alcácer Kibir: subsídios históricos. História e Genealogia, vol. V, 47-58. Lisboa: Ed. Casa Portuguesa.

GARCIA, José Manuel (2006). A historiografia portuguesa dos Descobrimentos e da Expansão (Séculos XV a XVII): autores, obras e especializações memoriais. 2 vols. (Dissertação de Doutoramento). Porto: Faculdade de Letras da Universidade do Porto.

GARCIA, José Manuel (2011). A Batalha de Alcácer Quibir e a cronística portuguesa. In Portugal e o Magrebe. Actas do 4. ${ }^{a}$ Colóquio de História Luso-Marroquina / Actes du IV Colloque d'Histoire Maroco-Lusitanienne (pp. 377-385). Lisboa / Braga: Centro de História de Além-Mar e Centro de Investigação Transdisciplinar Cultura, Espaço e Memória.

HERMANN, Jacqueline (1998). No reino do Desejado: A construcão do sebastianismo em Portugal, séculos XVI e XVII. São Paulo: Companhia das Letras.

HERMANN, Jacqueline (2006). El-Ksar El-Kebir: Narrativas e história sebástica na Batalha dos três reis - Marrocos, 1578. História: questôes \& debates, Curitiba, n. 45, 11-28.

INOCÊNCIO DA SILVA, Francisco (1860). Diccionario Bibliographico Portuguez. Tomo V. Lisboa: Imprensa Nacional.

INOCÊNCIO DA SILVA, Francisco (1862). Diccionario Bibliographico Portuguez: Tomo VI. Lisboa: Imprensa Nacional.

JANSSEN, Maarten (2014). TEITOK. URL: http://www.teitok.org/index.php?action=home.

Jornada de Africa del Rey D. Sebastião escrita por um homem africano. Edição por Júlio da CONCEIÇÃO PEDRO \& Fernando CALAPEZ (2004). Lisboa: Editora Livro Aberto.

Jornada del-rei dom Sebastião à África: Crónica de dom Henrique. Edição e Prefácio por Francisco de Sales Mascarenhas LOUREIRO (1978). Lisboa: Imprensa Nacional Casa da Moeda.

LEITÃO DE ANDRADE, Miguel (1629). Miscelânea do sítio de Nossa Senhora da Luz do Pedrogão Grande. Lisboa: Oficina de Mateus Pinheiro.

LOMBARDO, Elena (2015). Do "grande incêndio que com tam raro movimento a Berberia perturbou”: estudo e edição diplomática de um relato bistórico quinhentista (Dissertação de Mestrado). São Paulo: Faculdade de Filosofia, Letras e Ciências Humanas, Universidade de São Paulo. 


\section{ELENA LOMBARDO \& FILIPE ALVES MOREIRA}

LOMBARDO, Elena (2016). O Sumario de todas as cousas succedidas em Berberia: aspectos filológicos e linguísticos de sua transmissão manuscrita (Comunicação). In ALPES - Abriendo lineas en el pasado del Español. Kandersteg: inédito.

LOUREIRO, Rui (2018). Práticas de escrita entre os cativos portugueses em Marrocos: Alguns comentários à Crónica de Almançor. In Livro de resumos da conferência internacional "AlcácerQuibir: margens e contra-margens". Lisboa, 24 e 25 de maio de 2018, 43-44. Lisboa: CHAM - Centro de Humanidades.

LUND, Christopher (Ed.). (1980). Anedotas portuguesas e memórias biográficas da corte quinhentista. Coimbra: Almedina.

MELO, Francisco Manoel de (1660). Epanaphoras de varia historia portugueza, II: Naufragio da armada portugueza em França. Edição semidiplomática por Evelina VERDELHO. Lisboa: Oficina de Henrique Valente de Oliveira. Disponível em $<$ https://www.uc.pt/uid/celga/recursosonline/cecppc/textosempdf/06epanaforas >. Último acesso: 11 de abril de 2019.

MENDONÇA, Jerónimo de (1607). Jornada de Africa. Lisboa: Oficina de Pedro Craesbeek.

MONIZ, José António (1896) Inventario. Secção XIII - Manuscriptos. Lisboa: BN. Disponível em http://purl.pt/183/4/b-1272-a_PDF/b-1272-a_PDF_24-C-R0150/b-1272-a_0000_capacapa_t24-C-R0150.pdf. Último acesso: 11 de abril de 2019.

OLIVEIRA, Vítor Amaral de (Org.). (2002). Sebástica: bibliografia geral sobre D. Sebastião. Coimbra: Biblioteca Geral da Universidade de Coimbra.

QUEIRÓS VELOSO, José Maria de (1935). D. Sebastião 1554-1578. Lisboa: Empresa Nacional de Publicidade.

QUEIRÓS VELOSO, José Maria de (1950). Estudos históricos do século XVI. Lisboa: Academia Portuguesa de História.

Relação da vida d'Elrey D. Sebastião. Leitura, introdução e notas por Francisco de Sales de Mascarenhas LOUREIRO (1977). Separata da Revista da Faculdade de Letras, vol. II, 4 a série, 481559.

RIBEIRO, Luciano (1960). Colectânea de documentos acerca de D. Sebastião. Separata de Studia, $n .{ }^{\circ} \mathrm{V}$, Janeiro, 135-257. Lisboa: Centro de estudos históricos ultramarinos.

SANTOS, Frei Manuel dos (1735). História sebástica. Lisboa: Oficina de António Pedrozo Galram.

SÃO BOAVENTURA, Frei Fortunato de (1827). Historia chronologica, e critica da Real Abbadia de Alcobaça. Lisboa: Impressão Regia. 